\title{
Erratum: Unique electron polarimeter analyzing power comparison and precision spin-based energy measurement [Phys. Rev. ST Accel. Beams 7, 042802 (2004)]
}

J. M. Grames, C. K. Sinclair, J. Mitchell, E. Chudakov, H. Fenker, A. Freyberger, D. W. Higinbotham, M. Poelker, M. Steigerwald, M. Tiefenback, C. Cavata, S. Escoffier, F. Marie, T. Pussieux, P. Vernin, S. Danagoulian, V. Dharmawardane, R. Fatemi, K. Joo, M. Zeier, V. Gorbenko, R. Nasseripour, B. Raue, R. Suleiman, and B. Zihlmann (Received 28 May 2010; published 14 June 2010)

DOI: 10.1103/PhysRevSTAB.13.069901

PACS numbers: 29.25.Bx, 29.27.Hj, 29.30.Dn, 13.60.Fz, 99.10.Cd

This erratum corrects a typographical error in the final line of Eq. (5). It should correctly read

$$
\Psi_{n}=\left(\frac{g-2}{2 m_{e}}\right)\left\{\left[n \theta_{1}+(n-1) \theta_{2}\right] E_{0}+\frac{n}{2}\left[(n+1) \theta_{1}+(n-1) \theta_{2}\right] E_{1}+\frac{n(n-1)}{2}\left(\theta_{1}+\theta_{2}\right) E_{2}+\left[E_{0}+n\left(E_{1}+E_{2}\right)\right] \theta_{h}\right\} .
$$

However, all results and conclusions of the paper remain unaffected by this change, as the correct formula was implemented in the calculations used for the analysis. 